\title{
A Psicologia da Universidade de São Paulo e as relações raciais: perspectivas emergentes
}

\author{
Lia Vainer Schucman ${ }^{a^{*}}$ \\ Sylvia da Silveira Nunes ${ }^{b}$ \\ Eliane Silvia Costa ${ }^{a}$ \\ aUniversidade de São Paulo, Instituto de Psicologia (IPUSP). São Paulo, SP, Brasil \\ 'Universidade Federal de Itajubá (UNIFEI). Itajubá, MG, Brasil
}

\begin{abstract}
Resumo: O presente artigo visa apresentar a produção acadêmica sobre o tema raça e racismo elaborada no Instituto de Psicologia da USP (IPUSP). Para tanto, fizemos uma análise das teses e dissertações produzidas no IPUSP entre 1970 e 2012 e que utilizaram essas categorias para compreensão de fenômenos subjetivos, sociais e políticos. Dentre outros aspectos, constatamos que os trabalhos analisados se dividem principalmente em três grandes eixos, são eles: denúncia do racismo, modos de subjetivação do racismo e estratégias para superá-lo. No entanto, é possível considerar que são poucos os trabalhos que versam de forma sistemática acerca da desconstrução do racismo, bem como sobre metodologias e técnicas em que psicólogos poderiam contribuir para a luta antirracista na sociedade brasileira. Por assim dizer, ainda há uma lacuna no conhecimento de Psicologia e relações raciais que deveria ser aprofundado por psicólogos.
\end{abstract}

Palavras-chave: racismo, relações raciais, pós-graduação, psicologia.

\section{Introdução}

Estudos genéticos contemporâneos, tais como Pena (2008), provaram a não existência de uma demarcação biológica que diferenciaria os sujeitos em grupos raciais distintos. Ou seja, do ponto de vista genético, não existe raça. É por isso que, de maneira geral, esse tema não tem mais lastro entre os discursos científicos de cunho biológico. No entanto, a temática das relações e das desigualdades raciais ainda hoje tem sido objeto de diferentes estudos das ciências humanas, já que a raça ainda é um importante componente nas estruturas sociais.

No Brasil, raça é uma categoria que diferencia, hierarquiza e subjuga diferentes grupos marcados pelo fenótipo. A cor da pele, o formato dos lábios e do nariz, a textura e a forma do cabelo são alguns dos atributos físicos utilizados para diferenciar e hierarquizar os grupos raciais, alocados principalmente entre aqueles que compõem um grupo racial tido como branco e outro como negro. Em outras palavras, a despeito de não haver nenhum elemento genético que distinga potencialidades psíquicas, morais, culturais, intelectuais, entre brancos e negros, as relações sociais ainda são racializadas, sendo utilizadas as características físicas/biológicas como esteio para essa racialização e, portanto, para o racismo.

Entendemos que o racismo é um dos efeitos da crença de que existem raças. Diz respeito a todo fenômeno baseado no conceito de raça/cor e que promova distinções,

* Autora correspondente: liavainers@gmail.com preferências, exclusões e restrições entre os sujeitos em qualquer domínio da vida (Brasil, 1969). Ou ainda como afirmam Poliakov, Delacampagne e Girard (1977), o racismo cria fantasmas, teorias e práticas discriminatórias, com o único objetivo de afirmar a superioridade de um grupo em relação a outro. Nesse sentido, é possível visualizar o racismo anterior mesmo ao conceito de raça na história, a que os autores chamam de "protoracismo", como o que ocorreu na Arábia pré-islâmica, fato demostrado por Lewis (1982) a partir da análise de textos apócrifos ao Alcorão.

No presente artigo, a questão racial é abordada tal como foi postulada por Guimarães (2003): raça refere-se a uma categoria analítica empregada como recurso teórico-metodológico presente na realidade cotidiana, sendo também uma categoria nativa, a qual "tem sentido prático, efetivo. Ou seja, possui um sentido histórico, um sentido específico para um determinado grupo humano" (p. 95), ainda que, contraditoriamente, no dia a dia refira-se a um assunto silenciado.

Como é notório, no Brasil, não é de bom tom mencionar os temas raça e racismo. Fala-se não falando. Fala-se principalmente por meio das diferenças de classe. Todavia, circunscrever desigualdades raciais às de classe é uma forma de escamotear o racismo, já que ponderar sobre ele significa revelar a faceta pouco harmoniosa de nossa sociedade, a qual engendra e mantém profundas desigualdades sociais. É o que apontam estudos nacionais e internacionais, tais como os de Wieviorka (1991), Guimarães (2002, 2005) e Munanga (2004), os quais destacam o racismo como a explicação mais sólida para se compreender 
a perpetuação das desigualdades sociais e econômicas no Brasil, entre outras.

A construção social da raça e do racismo são os principais organizadores das desigualdades materiais e simbólicas vividas pelo povo brasileiro. Perpassam os modos de subjetivação e socialização dos sujeitos negros, brancos, mestiços/pardos e indígenas, nos mais variados espaços públicos e privados, estruturando as condições e possibilidades de trabalho, de estudo, de vínculo (incluindo o casamento e as relações amistosas), de liberdade, de lugar onde morar e a forma de morrer. Ver, por exemplo, o Mapa da Violência elaborado pelo Centro Brasileiro de Estudos Latino-Americanos (CEBELA) e pela Faculdade LatinoAmericana de Ciências Sociais, Sede Brasil (FLACSO), em 2013. Afeta a possibilidade de os negros garantirem o presente, planejarem o futuro, realizarem sonhos, satisfazerem necessidades. Igualmente, afeta as condições materiais e simbólicas dos brancos, que, de maneira geral, usufruem das situações mais privilegiadas.

Historicamente, reivindicações pela mudança desse cenário têm sido politicamente realizadas pelo Movimento Negro Brasileiro.' A partir dessas ações reivindicatórias, a preocupação e o enfoque dado ao racismo e às relações raciais na sociedade brasileira têm mudado nos últimos anos. Agências governamentais e programas específicos no âmbito dos governos federal, estadual e municipal têm sido criados com o intuito de diminuir as iniquidades provocadas pelo racismo.

A sociedade brasileira e, mais especificamente, o Estado brasileiro começam timidamente a responder às demandas da população negra organizada. Como exemplos de conquistas jurídicas e políticas podemos citar:

- $\mathrm{O}$ art. $5^{\circ}$ XLII da Constituição Federal, que decreta a prática do racismo como crime inafiançável e imprescritível ${ }^{2}$ (Brasil, 1988);

- $\quad$ O art. 68 ADCT da Constituição Federal, que estabelece o direito dos povos quilombolas de terem o título de domínio de terras onde vivem (Brasil, 1988);

- A Lei $\mathrm{n}^{0} 7.716$ de 1989 , que define os crimes resultantes de preconceito de raça ou de cor (Brasil, 1989);

1 Desde os primeiros tempos da instituição da República Brasileira, organizações compostas principalmente por negros têm sido protagonistas de resistências contra a discriminação racial em relação aos negros. São exemplos dessas organizações a Frente Negra Brasileira (FNB), a União dos Homens de Cor (UHC), o Teatro Experimental do Negro (TEN) sendo sua principal liderança Abdias do Nascimento - e o Movimento Negro Unificado (MNU), fundando em 1978, com uma agenda radicalmente combativa contra o racismo. Para detalhes sobre a história do Movimento Negro no Brasil ver, por exemplo, CPDOC-FGV (2007) e Domingues (2007)

2 Racismo e terrorismo são os dois únicos crimes imprescritiveis reconhecidos por nossa constituição.
- A criação da Secretaria de Políticas de Promoção da Igualdade Racial (SEPPIR) por meio da Medida Provisória ${ }^{\circ} 111$, de 21 de março de 2003, convertida na Lei ${ }^{\circ} 10.678$;

- A Lei Federal no 10.639 de 2003, que tornou obrigatório o ensino de História da África e da cultura afro-brasileira nas escolas de ensino fundamental e médio (Brasil, 2003a);

- A Lei no 12.519 de 2011, que institui o dia 20 de novembro como Dia Nacional de Zumbi e da Consciência Negra (Brasil, 2011);

- O reconhecimento em 2012, pelo Supremo Tribunal Federal, da política pública de cotas para negros nas universidades públicas brasileiras, como prática constitucional ${ }^{3}$;

- A Lei $n^{0} 12.711$ de 2012, que dispõe sobre reserva de vagas para o ingresso nas universidades federais e nas instituições federais de ensino técnico de nível médio (Brasil, 2012).

No tocante às produções teóricas, já sinalizamos o posicionamento usual das Ciências Biológicas atinente à ideia da não existência da raça como um diferenciador de potencialidades genéticas entre os grupos sociais; já as Ciências Humanas - com destaque às áreas da Antropologia, da História e da Sociologia - têm, em maior ou menor grau, versado sobre o que se convencionou chamar de raça social (Guimarães, 1999). Isso é a constatação de que a não existência de diferenças genéticas significativas entre negros e não negros não anula as desigualdades sociais que há entre a população negra e a branca, nem mesmo abole os estereótipos pejorativos atribuídos aos negros e os positivos adjudicados aos brancos.

O conceito de raça social ou política para os negros que se reconhecerem como tal é uma estratégia de afirmação pessoal, de mobilização social e negociação política. É, assim, uma ferramenta que possibilita a essa população reconhecer-se grupalmente e reivindicar mudanças.

Se há uma produção importante sobre esse tema nas Ciências Humanas, o mesmo não se verifica em uma área que pode ser entendida como pertencente tanto às Ciências Humanas como às Biológicas: a Psicologia. É por isso que, neste texto, queremos dar relevo à participação da Psicologia no campo das relações e desigualdades raciais relacionadas aos negros.

Consideramos que a Psicologia deveria ser uma das áreas do conhecimento alicerce para se pensar e enfrentar o racismo contra o negro, já que ele (o racismo) é uma modalidade de violência, de desigualdade política e, como tal, é (ou pode ser) promotor de persistente sofrimento psíquico vivido por e entre os negros.

Apesar da luta contra a discriminação racial e das preocupações em torno das relações raciais serem fundamentais para uma sociedade justa e humana, e embora, nas

3 Disponível em: http://www.stf.jus.br/arquivo/informativo/documento/ informativo663.htm 
últimas décadas, a Psicologia tenha produzido aportes relevantes sobre dores psíquicas e sobre o sujeito psíquico como sendo intrinsecamente sócio-político, encontramos poucos estudos nessa área que aprofundem a temática do racismo ou de outras nuances concernentes ao negro como sujeito político.

Nas grades curriculares das faculdades de psicologia brasileiras raramente encontramos menções ao tema da raça e do racismo em disciplinas obrigatórias.

Dada a escassez de trabalhos na área, o presente artigo visa mapear e analisar brevemente a produção acadêmica do Instituto de Psicologia da USP (IPUSP) acerca do tema em questão. Para tanto, fizemos uma apreciação das teses e dissertações produzidas no IPUSP que utilizaram essas categorias (raça e racismo) para a compreensão de fenômenos psicossociais.

Escolhemos o Programa de Pós-Graduação do IPUSP por se tratar do curso de Psicologia daquela que tem sido considerada a melhor universidade da América Latina ${ }^{4}$. Sendo um curso de uma universidade pública, espera-se que suas pesquisas tenham uma função social em relação ao ensino, à promoção cultural, ao fazer científico e ao desenvolvimento tecnológico - ainda que atualmente as produções universitárias nacionais não estejam livres das pressões do mercado, das exigências de produtividade e especialidade. $\mathrm{O}$ que não raramente obstaculiza a produção de um olhar político-social.

\section{Panorama das produções sobre relações raciais do Programa de Pós-Graduação do IPUSP}

O Programa de Pós-Graduação do IPUSP foi criado em 1970. Desde então, 2.916 trabalhos, entre teses e dissertações, foram apresentados até maio de 2012. Destes, apenas 15 abordaram a questão da raça e do racismo, o que representa menos de $0,5 \%$ do total de pesquisas realizadas. Em 2011, a média de defesa anual era de 39 dissertações e 32 teses $^{5}$. Atualmente, há cinco áreas de concentração no programa: (1) Neurociências e Comportamento (NEC); (2) Psicologia Clínica (PSC); (3) Psicologia Escolar e do Desenvolvimento Humano (PSA); (4) Psicologia Experimental (PSE); (5) Psicologia Social (PST).

Em ordem cronológica decrescente, o Anexo 1 apresenta as informações de identificação das quatro dissertações e onze teses, quais sejam: ano de defesa; autor; título do trabalho; tipo de trabalho; nome do orientador, área de concentração em que o trabalho foi realizado e as

4 De acordo com a lista elaborada pela Quacquarelli Symonds (QS), consultoria britânica especializada em educação superior, a USP lidera, pelo terceiro ano consecutivo (de 2011 a 2013), o ranking de melhores instituições de ensino superior da América Latina. Fonte: <www.folha.uol.com.br>, 28 maio 2013.

Além disso, neste ano, a USP foi considerada a $11^{\mathrm{a}}$ melhor universidade de países emergentes. Fonte: <www.terra.com.br>, 04 dez. 2013.

5 Fonte: <www.ip.usp.br>. categorias criadas por nós para breve análise dos trabalhos. Elas serão apresentadas no tópico três deste artigo.

O quadro mostra que somente três áreas de concentração (PSA, PST e PSC) têm trabalhos relacionados ao tema da raça, relações raciais e do racismo ${ }^{6} \mathrm{e}$ suas variações, como: identidade negra, movimento negro, branquitude etc.

Notamos que 10 dos 15 trabalhos foram realizados no departamento de PSA. Essa área é uma das mais antigas do Programa, foi criada em 1970, com o PSE, e tem 894 trabalhos defendidos. ${ }^{7} \mathrm{O}$ que significa afirmar que pouco mais de $1 \%$ das teses e dissertações desse departamento abordam o tema racial. É notável também que na área de psicologia social somente quatro trabalhos versaram sobre o racismo - sendo dois deles de autoras deste artigo. Se o racismo é um importante problema social, o é igualmente psíquico. Trata-se eminentemente de uma problemática psicossocial; todavia, apenas uma pesquisa fez parte do programa da Psicologia Clínica da USP.

Dos mais de 110 docentes do Programa de Pós do Instituto, apenas 11 , isto é, cerca de $10 \%$ do total, orientaram estudos voltados ao tema. Desses, somente duas professoras se debruçaram em mais de uma vez sobre a questão. Uma das primeiras orientações, até mesmo, foi feita por professor externo ao IPUSP, pelo professor Kabengele Munanga, do departamento de Antropologia da USP. ${ }^{8}$

No que diz respeito às teses e dissertações, o IPUSP inaugurou tardiamente seus trabalhos sobre a temática em questão. O primeiro deles foi defendido em 1991, cerca de duas décadas depois da formalização de seu programa de pós; mais de uma década depois da publicação de importantes trabalhos sociológicos sobre desigualdades raciais, dentre eles os de Hasenbalg (1979). Entre a primeira tese e a segunda passaram-se sete anos. Lacuna significativa de tempo. De lá para cá, de maneira geral, tem havido sobre o assunto uma defesa ou, quando muito, duas, por ano. Ainda assim, houve períodos em que esse tema de investigação não apareceu nos cerimoniais de defesa acadêmica, nos anos 2003, 2006-2008, e em 2011. No entanto, é interessante observar que foram desenvolvidas mais teses do que dissertações, respectivamente 11 e quatro.

\section{Algumas considerações sobre as teses e dissertações do IPUŞP}

A partir da leitura e análise de cada tese e dissertação, construímos categorias como chave de compreensão

\footnotetext{
6 Aqui é importante registrar que as categorias usadas como descritores na procura das pesquisas foram: raça, racial, racismo, racista (s), étnico-racial, negra $(0, s)$. Logo, trabalhos que possivelmente tangenciem a temática, mas não tiveram como foco principal o fenômeno do racismo ficaram fora desta análise.

7 Novamente, foram considerados os estudos realizados até maio de 2012.

8 Em 2010, nesse mesmo departamento, foi criada uma linha de pesquisa voltada especificamente para o campo das relações étnico-raciais. Atualmente, como parte integrante dessa linha estão sendo elaboradas quatro dissertações de mestrado sob orientação do professor Alessandro de Oliveira dos Santos.
} 
do fenômeno estudado, as quais estão vinculadas ao crivo que tivemos a partir de nossos referenciais. São elas: (a) denúncia do racismo; (b) modos de subjetivação do racismo; (c) estratégias de superação do racismo. Compreendemos que todos esses trabalhos, em maior ou menor grau, entrelaçam esses eixos entre si; todavia, escolhemos assim agrupá-los conforme nossa compreensão do foco central de análise dada pelos pesquisadores. Abaixo, apresentamos em cada categoria uma breve resenha dos trabalhos. Com isso, buscamos compreender quais são os principais temas abordados e as conclusões das pesquisas realizadas.

\section{a. Denúncia do racismo}

Estão presentes nessa categoria quatro teses que, por caminhos diferentes, mostraram em suas pesquisas a necessidade de denunciar o racismo como prática constante na vida cotidiana. São elas: as teses de Iolanda Oliveira (1998), Marly de Jesus Silveira (2002), Hildeberto Vieira Martins (2009) e de Sylvia da Silveira Nunes (2010).

Iolanda Oliveira (1998), em As desigualdades raciais vistas pelas crianças e pelos jovens, investigou como crianças e jovens, entre cinco e 15 anos, de estrato social baixo e médio, percebiam as desigualdades raciais na sociedade brasileira. A autora priorizou os temas habitação e trabalho como eixos a partir dos quais os alunos de uma escola pública de São Paulo revelariam como entendiam as relações raciais. Para tal, procedimentos como realização de desenho, de maquete e entrevistas foram utilizados. Além de alunos, foram entrevistados pais, professores e a presidente da Associação de Moradores do bairro onde a escola está situada.

A autora constatou que foi mais corriqueiro para os alunos representar em seus desenhos e falar sobre a pobreza do que sobre a raça. Ainda assim, os estudantes mostraram percepção das desigualdades raciais, para as quais a explicação apresentada por eles se referia a uma compreensão naturalizada da diferença.

Quanto aos pais, Oliveira (1998) salientou que os negros e pobres tiveram maior resistência em falar sobre o assunto do que os demais. Já os professores se mostraram mais sensíveis à questão racial do que os pais, o que não significa dizer que tiveram um discurso crítico sobre o racismo. Para a autora, eles também revelaram dúvidas sobre a discriminação racial ser um fator preponderante na condição de desvantagem do negro brasileiro. Além disso, em algumas ocasiões, falas preconceituosas foram proferidas por docentes.

A pesquisadora percebeu que a escola não problematizava significativamente nem as questões relativas à pobreza nem ao racismo. Ao se isentar de refletir sobre esses pontos, acaba perpetuando preconceitos, pois o silêncio sobre o racismo e a discriminação de classe ajuda a disseminá-los. Isso reafirma ainda mais a urgência da escola em trabalhar de forma crítica o problema das desigualdades raciais e de classe.

Ainda no âmbito da educação, apresentamos a tese Educação, diferenças e desigualdade: a contribuição da escola neste enfrentamento, de Marly de Jesus Silveira (2002), que analisou a abordagem do tema raça e racismo nos Parâmetros Curriculares Nacionais (PCN).

De acordo com a autora, nos PCN de 1997, o conceito de "Pluralidade Cultural" foi utilizado como se a diversidade cultural brasileira indicasse equanimidade entre as diferentes expressões culturais e como se não houvesse uma valorização de certas culturas em detrimento de outras. Para ela, tal conceito foi usado como uma forma atualizada do mito da democracia racial, pois ignora os conflitos nas relações de poder e silencia a violência e desigualdade racial de nosso país.

Salientou do mesmo modo que naquele texto do PCN não há referências críticas à escravização e às relações raciais; ao contrário, naquelas diretrizes governamentais para a educação no Brasil é reforçada a ideia de um "país hospitaleiro" às distintas "etnias".

A não utilização de conceitos consagrados no estudo das relações raciais - como o de raça e escravismo - foi por ela compreendida como uma dificuldade das políticas públicas educacionais de lidar com o tema racial e, por ampliação, de criar estratégias efetivas de combate às desigualdades raciais aqui existentes.

A autora criticou o fato da problemática do racismo ter ficado circunscrita a uma mera recomendação. Como sugestão, o professor que não se sente preparado para trabalhar o tema pode ignorá-lo. Não deveria depender apenas da decisão de uma ou outra escola, de um ou outro professor retratar essa questão, mas de uma política pública que desse condições efetivas e contínuas para que fosse abordada de forma a buscar um olhar crítico sobre a realidade brasileira.

Cabe registrar que esses dois estudos foram feitos antes da Lei Federal $\mathrm{n}^{\circ} 10.639$ (Brasil, 2003a), que tornou obrigatório o ensino de História da África e da cultura afro-brasileira nas escolas de Ensino Fundamental e Médio.

Pensando o racismo na instituição de ensino, Rosemberg (2000) constatou que a escola que o negro frequenta não é usualmente a mesma do branco, pois a primeira população está em grande parte presente em espaços educacionais e geográficos de qualidade inferior, ainda que se compare aos brancos do mesmo nível social. Nesse sentido, é possível considerar que o grupo social negro participa dos processos formais de escolarização brasileira em uma escola pior e mais excludente do que a que o aluno branco conhece.

Munanga (2005) afirmou que possíveis dificuldades no processo escolar da população negra, de modo geral, podem ter como uma das hipóteses explicativas a forma como a identidade negra tem sido socialmente construída; ou melhor, se a memória coletiva de um grupo é um dos pontos de partida da construção de sua identidade, é compreensível que as crianças negras tenham um rendimento pior na escola do que as brancas, já que a forma como a história dos negros é contada na escola se não é humilhante, é desumana, pelos frequentes estereótipos a eles imputados - do primitivismo animalesco à submissão 
escravista. As revoltas e as lutas dos negros pela liberdade só muito recentemente começam a ser parcialmente contadas nos livros didáticos.

Por outro lado, é sabido que, na contramão, alguns negros em função principalmente desses mesmos processos de humilhação e em um movimento de resistência a eles tornam-se bons alunos.' Em todo caso, seja para os discentes negros tidos como "fracassados" ou para "bons alunos" há custos subjetivos e sociais envolvidos em seus processos de aprendizagem. É crível considerar que ter tácita ou explícita a obrigação de ser bom aluno para não ficar preso à pecha de ser inferior exige sacrifícios quando se vem de um processo educacional desigual.

Do ponto de vista histórico, a tese de Hildeberto Vieira Martins (2009), intitulada As ilusões da cor: sobre raça e assujeitamento no Brasil, trouxe significativa contribuição no estudo do racismo, a qual é importante para ser também considerada no âmbito escolar.

O autor investigou a construção do discurso sobre o "elemento negro" no meio científico brasileiro de fins do século XIX até começo do século XX. Para tanto, realizou uma pesquisa bibliográfica e documental de textos dos chamados "homens de sciencia", sobretudo das obras de Nina Rodrigues e de autores da chamada "Escola Nina Rodrigues", tais como Juliano Moreira, Afrânio Peixoto, Heitor Carrilho, Leonídio Ribeiro e Artur Ramos. Esses autores preocupados com os rumos que o país tomaria no período pós-abolição sofreram influências das formulações teóricas racistas, de origem europeia, e que chegaram ao Brasil especialmente a partir de 1870 .

Martins (2009) analisou como o discurso racializado daqueles teóricos contribuiu para a legitimação de um discurso sobre o negro, ou antes, sobre o "elemento negro". $\mathrm{O}$ pesquisador usou essa expressão no sentido de marcar que ela se refere a uma construção social, a despeito de ser propagada como se fosse realidade. Em um país onde a mestiçagem é um dado, formular a ideia de que há elementos negros racialmente reais teve como finalidade, segundo o autor, inferiorizar esses sujeitos e responsabilizá-los pelas suas mazelas e, mais, pelos problemas sociais do país.

Considerar a raça como dado real é diferente de considerá-la uma construção político-sociológica. No primeiro caso, refere-se à crença ideológica de que a condição biológica do negro por si só determina sua realidade, isso é, sua escravização, pobreza e pouca escolaridade. No segundo caso, a raça utilizada como categoria construída sócio-politicamente diz respeito ao reconhecimento de que ela opera ideologicamente no processo de identificação e classificação dos grupos sociais legitimando e perpetuando desigualdades entre negros e brancos.

Para o pesquisador, tal discurso biologicamente racializado ocorreu pela homogeneização de grupos muito diversos de escravizados e seus descendentes, transformando-os em um problema "negro", o que naquela

9 Ver, por exemplo, os estudos sobre a questão das cotas no Ensino Superior de José Jorge de Carvalho (2005). compreensão redundava em um impedimento para o progresso do país.

$\mathrm{O}$ apagamento da resistência negra forjando um "elemento negro" por meio do discurso científico dos " $h o-$ mens de sciencia" já havia sido analisado por Schwarcz (1996).

As teorias científicas raciais brasileiras da passagem do século XIX para o XX possibilitaram uma pseudo verificação empírica das diferenças entre os humanos e, ainda hoje, permanecem ressoantes entre nós, brasileiros. É o que também constata Oliveira (1998), autora da primeira tese analisada na presente categoria. É o que se nota cada vez que o negro é associado, por exemplo, ao macaco.

Sylvia da Silveira Nunes (2010), em Racismo contra negros: um estudo sobre o preconceito sutil, partiu da constatação de que o racismo é um tema pouco abordado na Psicologia, a despeito de ser um problema social sério. Além disso, segundo a autora, pesquisas têm observado, em vários países, a frequência cada vez maior da forma sutil de preconceito em contraposição à diminuição da forma mais explícita. Nesse sentido, a pesquisadora buscou compreender essa nova fisionomia do racismo, a do preconceito sutil. Para tanto, Nunes (2010) realizou seus estudos em dois países, no Brasil e na Espanha; sendo que, dentre os vários grupos humanos possíveis de ser alvo de práticas racistas, enfocou sua pesquisa no racismo contra negros no Brasil e contra ciganos na Espanha. Embora existam diferenças na história de cada um desses grupos sociais, é comum entre eles o fato de estar há séculos em território brasileiro e espanhol, respectivamente, e persistirem as práticas discriminatórias contra eles.

A pesquisa combinou métodos quantitativo (escalas de preconceito sutil e flagrante de Pettigrew e Meertens) e qualitativo (entrevistas). No Brasil, 235 alunos universitários da USP responderam ao questionário e 71 estudantes de uma universidade pública, na Espanha. Destes, 15 foram entrevistados na pesquisa realizada no Brasil, e 4, na Espanha. Para a análise dos dados quantitativos, foram feitas provas estatísticas. Para as entrevistas, foram formuladas categorias de análise.

Os dados dos questionários apontaram:

(1) maior facilidade dos espanhóis em declarar o racismo;

(2) os homens mostraram maior preconceito do que as mulheres, tanto no Brasil quanto na Espanha;

(3) houve maior expressão de preconceito sutil do que de preconceito flagrante, nas amostras dos dois países;

(4) aproximadamente $75 \%$ da amostra brasileira se identifica como branca, mas apenas cerca de um terço tem ascendência branca. Ou seja, grande parte dos participantes são mestiços, mas se identificam como brancos.

Além disso, as entrevistas apontaram algumas questões da dinâmica do preconceito racial, tais como: o 
problema da sutileza na discriminação; as brincadeiras racistas; a culpabilização da vítima; a responsabilização do negro para a mudança de sua situação e, com isso, a recusa às propostas de ação afirmativa; a falsa neutralidade na abordagem do tema racial; e, finalmente, a não percepção da racialização presente.

Foram poucos os relatos racistas e não chegaram a compor uma categoria separada. Por outro lado, no tocante aos relatos, Nunes (2010) notou que a atitude de admissão do próprio racismo aponta um caminho para a superação do preconceito racial, uma vez que a coragem em assumir o próprio racismo leva à reflexão e à constatação de sentimentos racistas em diferentes momentos. Isso não quer dizer que tal processo seja simples e automático. Mas, de alguma forma, foi observado que além do "discurso politicamente correto" e da acusação de outras pessoas como racistas, há um "jogo" entre não querer ser visto como racista e desejar não ser racista, com a expressão sutil de ideias racistas. É nesse sentido que assumir o preconceito existente abre uma porta de mudança, ainda que não seja rápida e evidente.

Enfim, seja na educação ou no processo de subjetivação, as teses que compõem essa categoria se voltam para a necessidade de mostrar o racismo existente em nossa sociedade e denunciar os mecanismos e roupagens utilizados para culpabilizar o negro pela discriminação que passa e neutralizar a identidade do branco, também desumanizado na dinâmica de relações raciais.

\section{b. Modos de subjetivação do racismo}

Cinco teses e uma dissertação compõem a presente categoria. Os trabalhos apresentados abordam as consequências subjetivas da racialização e do racismo tanto para brancos quanto para negros. Maria Aparecida Silva Bento (2002) e Lia Vainer Schucman (2012) estudaram a branquitude e a identidade branca. Já Elizabeth Larkin Nascimento (2000), Isildinha Batista Nogueira (1998), Maria Aparecida Miranda (2004) e Eliane Silvia Costa (2012) estudaram a identidade negra, em diferentes espaços sociais e com diferentes grupos.

Maria Aparecida Silva Bento (2002), em sua tese Pactos narcísicos no racismo: branquitude e poder nas organizações empresariais e no poder público, estudou manifestações da identidade racial branca - denominada branquitude - em discursos de gestores de pessoal, chefes e profissionais de recursos humanos de duas prefeituras do Sudeste brasileiro. Partindo do pressuposto de que vivemos em uma sociedade racializada, tal racialização atingiria não só aos negros, mas também aos brancos. Assim, a autora buscou entender o que é ser branco no Brasil.

Por meio das entrevistas realizadas com sujeitos brancos, delineou uma série de características da branquitude, quais sejam:

(1) A cor da pele do branco é vivida como normahaja vista o exemplo do tom "cor da pele" para meia-calça;
(2) Há uma tendência para culpabilizar o negro pelas dificuldades vividas por ele e seu grupo social;

(3) Não se nota os negros nos espaços sociais de poder, isto é, não se nota a "parte negra do negro" isso porque reconhecer o sujeito negro como negro significaria reconhecê-lo como sujeito discriminado e remeter o branco a si próprio como branco, como cúmplice ou beneficiário de uma situação moralmente condenável;

(4) Há o reconhecimento da existência do racismo e da desigualdade racial no Brasil; porém, não se faz menção à discriminação vivida pelo negro cotidianamente, já que no país o tema das relações raciais é constantemente silenciado. Isso quer dizer que o fato de ser negada aos negros uma série de direitos foi visto pelos entrevistados como um problema em si mesmo ou como uma consequência direta da escravização. Porém, se o passado escravista traz efeitos para o negro, isso também ocorre com o branco, que se desumaniza ao ser supervalorizado.

Segundo a autora, a branquitude é uma determinada forma de viver o mundo, na qual os brancos usufruem de benefícios simbólicos e materiais perpetuados pela sua posição privilegiada no topo da hierarquia racial. Desse modo, o silêncio e a omissão dos brancos atinentes ao tema em questão seriam uma forma de manter a desigualdade racial.

Bento (2002) compreende que esse emudecimento dos brancos em relação ao racismo diz respeito a um pacto narcísico, isto é, a um pacto inconsciente firmado entre brancos cuja finalidade tácita é a manutenção de seus privilégios, sendo um deles a não responsabilização pelo passado escravista e pelos tempos atuais pautado em uma estrutura racista.

No que diz respeito às pesquisas que abordam a questão racial no Instituto de Psicologia da USP, consideramos a tese de Bento (2002) um marco paradigmático por colocar em debate a identidade branca. Essa é uma tendência nos Estados Unidos desde a década de 1990. Naquele país, o movimento de mudança nos estudos sobre racismo se deu quando os pesquisadores das Ciências Sociais e Humanas deslocaram o cerne de investigação dos "outros" racializados para o centro sobre o qual foi construída a noção de raça, ou seja, para os brancos. Esses novos enfoques foram chamados de estudos críticos sobre a branquitude (critical whiteness studies).

Trata-se de desfocar o olhar das identidades consideradas de margem e problematizar a construção da identidade considerada como referência de normalidade, de modo a denunciar a discriminação e, assim, desnaturalizar o preconceito. $\mathrm{O}$ trabalho de Bento repercutiu para além da produção dessa tese. A autora e Iray Carone, professora do IPUSP são responsáveis pela organização do livro Psicologia social do racismo: Estudos sobre branquitude 
e branqueamento no Brasil, lançado pela editora Vozes em 2002, livro este considerado pioneiro para os estudos de Psicologia e relações raciais no Brasil.

Contribuindo com os estudos sobre identidade racial branca, Lia Vainer Schucman (2012) em sua tese de doutorado intitulada: Entre o "encardido", o "branco" $e$ o "branquíssimo": raça, hierarquia e poder na construção da branquitude paulistana também usou o conceito de branquitude para a compreensão do racismo brasileiro. Para tanto, formulou como norte para seu trabalho as seguintes perguntas: quais os significados da branquitude em nossa cultura? De que forma ela se caracteriza? Quais as identificações em semelhanças e diferenças que os sujeitos brancos constroem com a branquitude? Quais os processos em que a raça opera na constituição dos sujeitos como brancos? E como a própria ideia de raça e os valores da branquitude diferenciam e hierarquizam internamente $o$ grupo de brancos em nossa sociedade?

A pesquisa de campo foi desenvolvida por meio da realização de entrevistas e conversas informais com sujeitos de diferentes classes sociais, idade, sexo e que se autoidentificaram como brancos. As análises demonstraram que há por parte desses sujeitos a insistência em discursos biológicos e culturais hierárquicos do branco sob outras construções racializadas (negros; indígenas e japoneses); e que, portanto, o racismo ainda faz parte de um dos traços unificadores da identidade racial branca como já havia apontado Maria Aparecida Bento e outros autores.

Contudo, o trabalho da autora traz uma nova contribuição para os estudos da branquitude brasileira, pois os achados de sua pesquisa demonstraram que os significados construídos sobre a branquitude exercem poder sobre 0 próprio grupo de indivíduos brancos, marcando diferenças, fronteiras e hierarquias internas ao grupo. Essas diferenças foram apontadas como produzidas pela própria ideia de raça construída no século XIX, pois o valor da branquitude está vinculado à origem étnica europeia e ao eurocentrismo e que, portanto, há uma hierarquia entre os brancos que se associa a quanto um branco tem dessa origem.

Assim sendo, a branquitude é deslocada dentro das diferenças de origem, regionalidade, gênero, fenótipo e classe, o que demonstra que a categoria branca é uma questão internamente controversa e que alguns tipos de branquitude são marcadores de hierarquias da própria categoria.

Elizabeth Larkin Nascimento (2000) em $O$ sortilégio da cor: identidade afrodescendente no Brasil fez uma análise do racismo brasileiro e da identidade negra por meio de uma epistemologia afrocentrada. A partir desse referencial, e com o intuito de descolonizar os saberes e as produções acadêmicas brasileiras de uma perspectiva eurocentrada, trouxe relevante contribuição sobre a questão do negro na diáspora, localizando-o não como objeto de estudo, mas como sujeito de sua história, isto é, como agenciador de lutas e saberes. Nesse sentido, a tese da autora nos mostra como os movimentos negros brasileiros foram e são fundamentais para a construção de imagens positivas daqueles que sofrem a violência racista.

A autora nomeou o tipo de racismo brasileiro como "sortilégio da cor", pois a ideologia dominante da democracia racial no Brasil teria estruturalmente acarretado uma aparente invisibilidade da questão racial, sendo uma das estratégias para atingir essa invisibilidade a representação do grupo racial negro por meio do uso de uma ampla gama classificatória de cor. Para tanto, levar-se-ia em conta critérios de natureza estética, sendo a cor um signo da celebração da mistura de raças, a noção de origem étnica ou racial não teria um papel, o que encobriria e "aparentemente" não estimularia o racismo.

O "sortilégio de cor", ou seja, a "desracialização" e a "colorização" dos negros brasileiros daria ensejo para a construção do que denominou de "Branco Virtual", referindo-se ao branco que assume e se engaja, mesmo de forma inconsciente, nos processos de racismo calcado na crença de que os sujeitos negros são coloridos - morenos, mulatos... -, ou seja, tratar-se-ia de sujeitos com matizes de pele identificáveis, diferentemente do branco, que virtual e ideologicamente teria uma identidade racial normal, fixa, por isso mesmo, imune a questionamentos.

Há ainda outros três trabalhos que tratam da questão da subjetivação do racismo na constituição de sujeitos negros, os quais se fundamentaram principalmente no referencial psicanalítico.

A partir dos dados de sua pesquisa de doutorado Significações do corpo negro, Isildinha Batista Nogueira (1998) afirmou que a dominação racial atinge a constituição dos sujeitos negros em todas as classes sociais. Com base na metapsicanálise lacaniana, propôs um modelo dos processos psíquicos atinentes a essa dominação que envolveria o ideal de ego branco (como efeito psíquico da ideologia do branqueamento) e também a dissociação narcísica da imagem do corpo. A falta de brancura seria vivida pelo negro como privação, e o branco seria visto como detentor daquilo que falta. Assim, para o negro a experiência cotidiana do racismo daria base para a recusa de seu corpo negro.

A autora parte da concepção do corpo como unidade significante e, dessa forma, quando o sujeito negro toma consciência da existência do racismo, tenderia a recusar seu próprio corpo. Pois, a partir de seu referencial teórico, o sujeito se constituiria psiquicamente por meio do olhar do outro, e o negro nesse confronto depararia com um olhar que reconhece nele o significado negativo que a pele negra historicamente carrega, tais como preguiça, sexualidade exacerbada, tendência ao crime e à violência etc.

Assim, "ser negro" corresponde a uma categoria incluída num código social que se expressa dentro de um campo semântico no qual o significante "cor negra" encerra vários significados. $\mathrm{O}$ "ser negro" remete não só a posições inferiores, mas também a características biológicas atribuídas aos brancos. Não se trata de significados explicitamente assumidos, mas de sentimentos presentes, restos de um processo histórico e ideológico que persistem numa 
zona de associações possíveis e que podem, a qualquer momento, emergir de forma explícita (Nogueira, 1998).

Já a dissertação de mestrado $A$ beleza negra na subjetividade das meninas -"um caminho para as Mariazinhas", de Maria Aparecida Miranda (2004), teve como objetivo entender como meninas negras pré-adolescentes entre 11 e 13 constroem suas identidades em uma sociedade racista. $\mathrm{O}$ trabalho da autora também se baseou na metapsicanálise lacaniana e trouxe contribuições importantes para pensarmos o racismo na constituição de sujeitos negros não só no Brasil, uma vez que a autora entrevistou grupos de meninas em São Paulo e em Maputo, capital de Moçambique.

Miranda (2004) relata os efeitos subjetivos da discriminação racial, que "falam de dor, sofrimento, sentimento de humilhação que levam a mutilações como arrancar os cabelos ou raspar a pele com uma lâmina. Mostram o embaraço e a vergonha com que os sujeitos se apresentam" (p. 143). Nesse sentido, a autora cita Nogueira (1998) quanto à reflexão que faz sobre a violência racista, a qual pode levar o sujeito a estabelecer uma relação persecutória contra seu próprio corpo.

A autora analisou diferentes momentos em que as meninas pesquisadas mostraram a presença do estereótipo, preconceito racial, discriminação e humilhação em suas vidas, o que, por vezes, as levavam à paralisia, vergonha $\mathrm{e}$ ao silêncio. No entanto, a pesquisadora concluiu que não é o lugar do branco que elas desejam nem mesmo a brancura, mas sim uma ressignificação do lugar do negro em nossa sociedade.

Eliane Silvia Costa (2012), na tese de doutorado Racismo, política pública e modos de subjetivação em um quilombo do Vale do Ribeira, elaborou o primeiro estudo do Programa de Pós do IPUSP voltado para a temática quilombola. Pesquisou uma das primeiras comunidades negras rurais do estado de São Paulo a conquistar o título de domínio de terras quilombolas.

A autora buscou compreender se, para aquela comunidade, a política pública de titulação de terras opera como dispositivo contra o racismo. Investigou como se dá o trânsito, a passagem, as sustentações e as transformações que ocorrem entre o âmbito estrutural - o da ideologia racista e da política pública -, o intersubjetivo e o intrapsíquico.

Como resultado de sua pesquisa constatou-se que a política pública voltada para os moradores do quilombo estudado convoca-os a entrar em contato com os efeitos do escravismo e do racismo. Todavia, ainda falta uma política articulada entre os diferentes níveis governamentais e voltada para a temática racial que lhes dê o devido apoio. A política implantada dedica-se à condição de pobreza da comunidade, mas falta um olhar que faça uma vinculação explícita com o rebaixamento colonial e pós-colonial de cunho racista imposto aos quilombolas.

Não por acaso, entre os entrevistados ainda não foi gestado coletivamente um discurso potente contra a ideologia racista; no entanto, estão atentos às situações de desigualdades por eles vividas e conhecem caminhos para enfrentá-las.

No tocante ao modo como se identificaram racialmente, nenhum entrevistado adulto revelou o anseio de ser branco e, mais do que isso, as famílias cujas histórias antepassadas tiveram a marca da negritude gestada como algo a não ser temido reconheceram-se prontamente como negras. Trata-se de famílias que mantiveram íntegros seus vínculos familiares, comunitários e culturais ancestrais. Nesses casos, os golpes do escravismo e do racismo recebidos pelas gerações precedentes foram em algum nível memorizados, elaborados e transmitidos conscientemente à geração seguinte. Por outro lado, nas famílias cuja imagem do negro ainda está conectada à do escravizado parece ser mais difícil assumir-se para o outro como negro. Nesses casos, os sujeitos comumente se reconheceram como morenos. Contudo, lá o termo moreno é polissêmico e é empregado de forma a não significar tão-somente negação da negritude.

Tal termo tem sido usado como sinônimo de humanidade; como oposição a branco; para indicar intermediação entre o claro e o escuro; como tentativa de amenizar os efeitos deletérios historicamente propagados pelo racismo, já que, no Brasil, trata-se de uma palavra definidora de uma identidade ideologicamente aceitável, ou quase.

Do ponto de vista dos processos intersubjetivos, de acordo com Costa (2012), a ideologia opera psiquicamente por meio de alianças psíquicas que molduram os sujeitos e seus grupos. Como hipótese teórica, os entrevistados ao se assumirem como morenos, por exemplo, para amenizar suas dores, o fazem por meio de alianças defensivas inconscientes contra o racismo. Tais alianças, segundo Kaës (2011), possibilitam aos sujeitos se organizem inconsciente e positivamente quanto a conteúdos psíquicos toleráveis e, ao mesmo tempo, organizamse defensivamente a partir de renúncias do que é insuportável.

\section{c. Estratégias de superação do racismo}

Nessa categoria, optamos por comentar trabalhos que apresentam propostas de superação do racismo tanto nas questões relativas à macroestrutura da sociedade quanto nas relações intersubjetivas. Os pesquisadores que se debruçaram sobre esse tema foram: Irene Sales Souza (1991), Ricardo Frankilin Ferreira (1999), Kiusam Regina Oliveira (2001), Osmar de Paula Pinto (2001) e Guilherme Scandiucci (2005).

As propostas, de modo geral, discorrem sobre possibilidades que dizem respeito a como os sujeitos negros por meio da conscientização do racismo de nossa sociedade se fortaleceram para enfrentá-lo cotidianamente, tanto individualmente como fazendo parte de grupos e movimentos sociais que lutam contra a opressão imposta à população negra.

Irene Sales Souza (1991) inaugurou os estudos da temática racial no Programa da Pós do IPUSP por meio de sua tese Resgate da identidade na travessia do movimento 
negro: arte, cultura e política, na qual aponta a importância dos movimentos sociais negros e da militância no processo de superação do racismo pelo próprio sujeito negro.

A autora fez uma análise de dois grupos de movimentos sociais negros: o Movimento Negro Unificado de Franca (MONUF) e Grupo Travessia de Ribeirão Preto. O objetivo da pesquisa foi entender como a participação dos militantes produz e transforma a identidade dos sujeitos envolvidos.

Segundo Souza (1991), a participação no grupo leva o militante a recuperar os valores da cultura e da história do negro e a redefinir sua identidade por meio de um processo de reconstrução interior que o instiga a rever padrões introjetados. A pesquisadora concluiu que os grupos se apresentam como ponto de referência aos sujeitos que deles participam, dando segurança para o enfrentamento da discriminação, fornecendo material informativo e atuando como memória do ego grupal. Desta forma, ambos os grupos obtêm conquistas sociais, culturais e políticas.

Ricardo Frankilin Ferreira (1999), em sua tese de doutorado intitulada Uma história de lutas e vitórias: a construção da identidade de um afrodescendente brasileiro, propôs um modelo sobre como a identidade do negro brasileiro se constrói, visando ações concretas para o desenvolvimento de identidades positivamente afirmadas.

Tal modelo descreve o desenvolvimento de um processo de deslocamento do racismo subjetivado pelo negro para um senso positivo da identidade negra. O autor pontuou como esse movimento se dá numa estreita conexão emocional com outras pessoas e registrou a constituição dessa identidade em quatro estágios. São eles: Estágio de Submissão; Estágio de Impacto; Estágio de Militância e Estágio de Articulação.

O estágio de submissão corresponde à subjetivação e aceitação da ideologia do branqueamento construída em nossa sociedade. Assim, haveria uma desvalorização do mundo negro e os sujeitos negros referenciar-se-iam em valores brancos. Para o autor, a permanência nesse estágio pode causar nos sujeitos negros sofrimento psicológico, pois o indivíduo tem a sensação de não se 'encaixar' em nenhum grupo. Entretanto, se ele gradualmente toma consciência da desvalorização a qual está submetido, pode iniciar um movimento na direção de uma transformação, o que pode levá-lo ao estágio seguinte, o de impacto, sendo que "a situação de impacto não é determinada por um único fato, mas sim através do efeito cumulativo de uma sucessão de pequenos episódios vividos pela pessoa, levando-a cada vez mais a tomar ciência de ser rejeitada" (p. 75) não pela sua personalidade, mas em função do racismo.

Nesse estágio, ao se dar conta da realidade, do fato de que não é branco, o sujeito teria condições de sair do estágio de submissão; assim, o sujeito compreenderia que ser negro faz parte de sua constituição como sujeito. É nesse ponto que usualmente o sujeito começa a incluir aspectos da negritude em sua identidade e tem a possibilidade de passar para o estágio de militância, o qual tem como característica a adesão do sujeito a movimentos sociais negros, a luta antirracista, a incorporação de signos e símbolos da negritude no corpo, assim como uma procura pela estética negra. $\mathrm{O}$ fechamento em torno de suas novas referências pode estagnar o sujeito nesse estágio, acarretando, quiçá, a preservação do mesmo padrão de subjetividade em que o sujeito pretendia transformar.

Após esse fechamento no próprio grupo, aos poucos, o sujeito poderá novamente se abrir para a alteridade, já que sua identidade negra agora é percebida positivamente pelo próprio sujeito. Dessa forma, há a possibilidade do sujeito passar para o próximo estágio, o da articulação, no qual o sujeito se vê como pertencente ao grupo de negros, incorpora isso de forma positiva, entende que inúmeras situações adversas acontecem pelo fato de estar inserido em uma sociedade racista - deixando de culpabilizar os negros pela conjuntura adversa na qual, mormente, se encontram - e também consegue se articular com sujeitos de grupos étnicos e raciais diversos.

Ferreira (1999), ao fazer esse modelo de compreensão da identidade negra brasileira e dos estágios necessários para a superação do racismo introjetado pelo próprio negro, aponta que esses estágios não fazem parte da personalidade dos sujeitos nem tampouco acontecem progressivamente um após o outro, assim como não sugere uma sequência linear, mas sim a ocorrência de processos transitórios na construção da subjetividade, os quais estariam ligados às circunstâncias específicas.

Kiusam Regina Oliveira (2001), em sua dissertação Duas histórias de autodeterminação: a construção da identidade de professoras afrodescendentes, com o objetivo de estudar a identidade de professoras negras, realizou entrevistas enfocando a vivência delas na escola como alunas e docentes. A autora procurou pessoas que tivessem lecionado na década de 1950, pela escassez de trabalho sobre professores negros nesse período.

Segundo a autora, sobre a vivência que as professoras tiveram quando alunas, as entrevistadas relataram situações de humilhações, xingamentos e injustiças. A propósito, uma delas teve dificuldade de fazer a matrícula na escola, pelo fato de ser negra. Como professoras, ambas comentaram que quaisquer reivindicações que fizessem, como resultado, sofreriam alguma punição. Uma delas passou pela situação extremada de ter sido exonerada após ter reivindicado os mesmos direitos de uma professora branca que realizava trabalho semelhante ao dela. A outra entrevistada relatou que uma professora branca se recusou a trabalhar com ela e, como se não bastasse, em seguida, ela (a professora negra) fora transferida de escola.

Apesar da violência racial vivida pelas entrevistadas como alunas e professoras, a pesquisadora notou um caminho de lutas traçado por elas, de modo a configurar um processo chamado por ela de autodeterminação.

Ao estudar a identidade dessas professoras, a autora dialogou com os estágios estudados por Ferreira (1999) e notou estágios que progridem e regridem, de forma 
alternada. De todo modo, ainda que não apresente estágios nomeados da mesma forma que Ferreira (1999), Oliveira (2001) constatou momentos diferentes da forma como a identidade das entrevistadas foi se construindo sendo comum às duas professoras o combate frequente contra o racismo em busca da própria realização como pessoa.

Duas dissertações finalizam este estudo, ambas relacionadas ao movimento negro.

Osmar de Paula Pinto (2001), em sua dissertação de mestrado Da descoberta de si mesmo à luta contra a exclusão: visões de militantes do movimento negro de São Paulo sobre a questão racial, partiu do pressuposto que a militância é uma das formas de luta contra a exclusão e superação do racismo, bem como uma forma de construir uma identidade positiva para a população negra. Porém, a partir da pouca participação dos negros no Movimento, Pinto (2001) buscou compreender os discursos dos militantes, a fim de identificar como se dá a comunicação entre aqueles e a população negra.

$\mathrm{O}$ pesquisador entrevistou dez militantes do Movimento Negro de São Paulo, procurando localizar e analisar, em seus discursos, as concepções sobre o Movimento, a militância e a não militância. Além disso, o autor investigou o motivo pelo qual diferentes entidades do Movimento Negro têm dificuldades em encontrar adesão da própria população negra paulista aos movimentos sociais negros.

Sobre o distanciamento entre o Movimento Negro e a população negra, a principal hipótese levantada pelo autor diz respeito à diferença de perfil social existente entre esses dois grupos; uma vez que, enquanto o primeiro é composto em sua maioria por uma população com nível superior, tendo situação profissional, posições ideológicas e participação política bem definidas, o segundo se caracteriza por uma população com baixa renda e escolaridade, bem como por pouco comprometimento ideológico com mudanças sociais favoráveis ao negro. Esses grupos participariam, pois, de mundos com discursos e pontos de vida que não coincidem. Com base nas entrevistas realizadas por Pinto (2001), essas diferenças produziriam barreiras na comunicação entre esses grupos.

Já Guilherme Scandiucci (2005), fundamentado na Psicologia Analítica, estudou o hip hop como forma de expressão cultural da juventude negra em sua dissertação Juventude negro-descendente e a cultura hip hop na periferia de São Paulo: possibilidades de desenvolvimento humano sob a ótica da psicologia analítica. Várias fontes de informação, tais como observações, entrevistas, depoimentos e letras de música foram utilizadas para a realização da pesquisa.

$\mathrm{O}$ autor analisou o hip hop como uma forma de expressão das dificuldades e discriminações da juventude negra da periferia. Para além da denúncia contida nas letras, principalmente no início do movimento, o autor considera que o hip hop auxilia os jovens a construírem uma identidade positiva, funciona como apoio para a superação de problemas vivenciados cotidianamente; dentre eles, a discriminação racial. Além disso, o autor considera que, das dificuldades encontradas pelo Movimento Negro de "adentrar" na realidade da periferia, o hip hop se mostra como uma possibilidade de comunicação mais fácil com os negros pobres.

Tanto o hip hop quanto o rap, segundo Scandiucci (2005), são expressões que ampliam a consciência e operam, de alguma forma, como função compensatória do self cultural. A experiência cultural propiciada seria uma possibilidade de "renascer almas", pois o movimento hip hop valoriza a beleza e as qualidades negras e permite a ressignificação do ser negro constituindo uma forma de recriar a africanidade.

\section{Considerações finais}

Na construção deste artigo tivemos como intuito elaborar um material que apresente as pesquisas do Programa de Pós-Graduação do Instituto de Psicologia da USP sobre a temática racial, contribuindo então para a divulgação dessa produção.

Nesse processo, procuramos analisar as principais temáticas estudadas, bem como as lacunas dessa produção. A partir da leitura pudemos perceber que, dentro da área da Psicologia, de maneira geral, os trabalhos abrangeram diferentes recortes de investigação.

Os pesquisadores do Instituto deram relevo às problemáticas que perpassam (a) a esfera política, como é o caso das pesquisas voltadas para a área educacional e a quilombola, assim como aquelas que se dedicaram aos movimentos sociais e culturais; (b) as produções teóricas atinentes ao racismo, como a tese acerca dos discursos sobre o negro no meio científico brasileiro; (c) as diferentes modalidades de expressão do racismo, como os estudos sobre o preconceito sutil e branquitude; (d) a dimensão identitária, especialmente no que concerne ao entendimento dos efeitos psicossociais do racismo, seja em relação à afirmação ou negação do negro como negro, ou mesmo da relação dele com seu corpo.

Tais estudos tiveram como preocupação principal denunciar a existência do racismo no Brasil e compreender os modos como ele é subjetivado. No tocante às estratégias de superação do racismo, elas apareceram de forma pontual, ainda que relevantes.

Ainda, cabe dizer que todos esses estudos apresentam um diferencial em relação aos estudos de Psicologia e relações raciais que haviam sido produzidos anteriormente por psicólogos do início do século passado, como os de Raimundo Nina Rodrigues, os quais deram base para a consolidação de um modelo psicofísico de explicação sobre o que foi chamado de "o problema do negro brasileiro".

Os trabalhos do IPUSP vão ao encontro da produção das Ciências Sociais posterior aos anos 1960 que apontam a categoria raça como uma construção sócio-histórica. Portanto, são produções relevantes para pensarmos o racismo do ponto de vista psicossocial e não psicologizante, 
pois não localizam no sujeito discriminado o responsável pela discriminação racial que vive cotidianamente. Por fim, os trabalhos tomaram a raça como uma construção social e, assim, focalizaram as relações de poder, evidenciando a força dessa categoria como fator de diferenciação e de hierarquização social.

A denúncia do racismo e da discriminação ainda se faz necessária, talvez pela negação histórica do racismo na sociedade brasileira. Os estudos sobre modos de subjetivação do racismo, de um lado, aparecem com a função de salientar como a representação negativa dos negros em nossa sociedade atua de forma violenta sobre a própria subjetividade do sujeito negro. A própria autodepreciação torna-se uma forte estratégia de opressão sobre os sujeitos pertencentes a grupos cuja imagem foi deteriorada. Dessa forma, a transmissão de uma imagem positiva de ser negro pela narrativa familiar, educacional e comunitária, assim como pela política de reconhecimento, pela estética como a do hip hop e pelos movimentos sociais apareceram como formas vitais para a constituição positivada dos indivíduos.
São poucas as pesquisadas realizadas, apenas quinze. Ainda assim, quiçá, podem dar lastro para o campo teórico e técnico da Psicologia em suas diferentes ramificações. Da clínica à política. Do âmbito social ao cultural. Todavia, é possível dizer, não tiveram como intuito central versar sobre como o psicólogo e a Psicologia podem e devem contribuir de forma sistêmica e abrangente com o desmantelamento do racismo.

Consideramos que enfrentar o racismo exige por parte da Psicologia - como ciência e como profissão - colaborar com a compreensão dos processos políticos e psicossociais atinentes ao racismo tanto quanto oferecer aporte para a transformação das relações socioeconômicas, dos padrões culturais e das formas de produzir e reproduzir a história brasileira. Assim, parece ser preciso que pesquisadores da área se indaguem sobre a necessidade de formular e sistematizar teorias, metodologias e técnicas que contribuam mais efetivamente com a luta antirracista nessas diferentes dimensões.

\title{
The psychology of the University of São Paulo and Racial Relations: Emerging Perspectives
}

\begin{abstract}
This paper aims to present the academic production on the theme of race and theme developed at the Institute of Psychology at USP (IPUSP). Therefore, we analised theses and dissertations produced at IPUSP between 1970 and 2012 that made use of these categories to understand subjective, social, and political phenomena. Among other aspects, we found that the studies analyzed are divided mainly into three main areas, namely: denouncing racism, ways of subjectivation of racism, and strategies to overcome it. However, it is arguable that there are few studies that deal systematically with the deconstruction of racism, as well as with methodologies and techniques through which psychologists could contribute for the anti-racist struggle in Brazilian society. So to speak, there is still a gap in knowledge of psychology and race relations that should be looked deeper into by psychologists.
\end{abstract}

Keywords: racism, racial relations, postgraduation, psychology.

\section{La Psychologie et les relations raciales: perspectives émergentes à l'Université de São Paulo}

Rèsumé: L'article suivant fait état de la production académique sur le thème de la race et du racisme élaborée à l'Institut de Psychologie de la I'Université de São-Paulo (IPUSP). Dans ce but, il propose une analyse des thèses et des mémoires produits à I'IPUSP entre 1970 et 2012, et ayant utilisé ces catégories pour la compréhension des phénomènes subjectifs, sociaux et politiques. Parmi d'autres aspects, nous constatons que les travaux analysés se divisent principalement en trois grands axes, qui sont : la dénonciation du racisme, les modes de subjectivation du racisme et les stratégies pour le surmonter. Toutefois, il est possible de constater la rareté des travaux qui traitent de façon systématique la déconstruction du racisme, tout comme des méthodologies et des techniques grâce auxquelles les psychologues pourraient contribuer à la lutte antiraciste dans la société brésilienne. En d'autres termes, il existe encore une lacune dans la recherche sur les relations raciales en psychologie qui devrait être approfondie par les psychologues.

Mots-clés: racisme, relations raciales, thèses et mémoires, Psychologie.

\section{La Psicología de la Universidad de São Paulo y las relaciones raciales: perspectivas emergentes}

Resumen: El presente artículo presenta la producción académica sobre el tema raza y racismo elaborada en el Instituto de Psicología de la USP (IPUSP). Para ello, hicimos un análisis de las tesis y disertaciones producidas en el IPUSP entre 1970 y 
2012, y que utilizaron esas categorías para la comprensión de fenómenos subjetivos, sociales y políticos. Entre otros aspectos, constatamos que los trabajos analizados se dividen principalmente en tres grandes ejes, estos son: denuncia del racismo, modos de subjetivismo del racismo y estrategias para superarlo. Mientras tanto, es posible considerar que son pocos los trabajos que tematizan de forma sistemática la desconstrucción del racismo, así como sobre metodologías y técnicas en las que los psicólogos podrían contribuir para la lucha anti-racista en la sociedad brasileña. En otras palabras, hay una laguna en el conocimiento de Psicología y relaciones raciales que debería ser profundizado por los psicólogos.

Palabras clave: racismo, relaciones raciales, posgrado, psicología.

\section{Referências}

Bento, M. A. S. (2002). Pactos narcísicos no racismo: branquitude e poder nas organizações empresariais e no poder público (Tese de doutorado). Instituto de Psicologia, Universidade de São Paulo, São Paulo.

Brasil. (1969). Decreto $n^{\circ} 65.810$, de 8 de dezembro de 1969. Promulga a Convenção Internacional sobre a Eliminação de todas as Formas de Discriminação Racial. Recuperado de http://portal.mj.gov.br/sedh/ct/legis_ intern/conv_ int_eliminacao_disc_racial.htm

Brasil. (1988). Constituição da República Federativa do Brasil. Brasília, DF: Senado.

Brasil. (1989). Lei $\mathrm{n}^{\circ} 7.716$, de 05 de janeiro de 1989. Define os crimes resultantes de preconceito de raça ou de cor. Diário Oficial da União, Brasília, DF, retificada em 09 de janeiro de 1989. Recuperado de http://www.planalto. gov.br/ccivil_03/leis/17716.htm

Brasil. (2003a). Lei $n^{\circ}$ 10.639, de 09 de janeiro de 2003. Altera a Lei $\mathrm{n}^{\circ}$ 9.394, de 20 de dezembro de 1996, que estabelece as diretrizes e bases da educação nacional, para incluir no currículo oficial da Rede de Ensino a obrigatoriedade da temática "História e Cultura AfroBrasileira", e dá outras providências. Recuperado de http://www.planalto.gov.br/ccivil_03/leis/2003/110.639. $\mathrm{htm}$

Brasil. (2003b). Medida Provisória n ${ }^{\circ} 111$, de 21 de março de 2003, convertida na Lei 10.678, de 23 de maio de 2003. Cria a Secretaria Especial de Políticas de Promoção da Igualdade Racial, da Presidência da República, e dá outras providências. Recuperado de www.planalto.gov. br/ccivil_03/mpv/Antigas_2003/111.htm

Brasil. (2011). Lei $n^{\circ}$ 12.519, de 10 de novembro de 2011. Institui o Dia Nacional de Zumbi e da Consciência Negra. Recuperado de http://www.planalto.gov.br/ ccivil_03/_Ato2011-2014/2011/Lei/L12519.htm

Brasil. (2012). Lei $n^{\circ}$ 12.711, de 29 de agosto de 2012. Dispõe sobre o ingresso nas universidades federais e nas instituições federais de ensino técnico de nível médio e dá outras providências. Recuperado de http://www. planalto.gov.br/ccivil_03/_Ato2011-2014/2012/Lei/ L12711.htm

Centro Brasileiro de Estudos Latino-Americanos, \& Faculdade Latino-Americana de Ciências Sociais Sede Brasil. (2013). Mapa da violência 2013. Recuperado de http://www.mapadaviolencia.org.br/mapa2013_armas. php

Carvalho, J. J. (2005). Inclusão étnica e racial no Brasil a questão das cotas no ensino superior. São Paulo, SP: Attar.

Costa, E. S. (2012). Racismo, política pública e modos de subjetivação em um quilombo do Vale do Ribeira (Tese de doutorado). Instituto de Psicologia, Universidade de São Paulo, São Paulo.

CPDOC-FGV. (2007). Histórias do movimento negro no Brasil: depoimentos ao CPDOC. Rio de Janeiro, RJ: Pallas.

Domingues, P. (2007). Movimento Negro Brasileiro: alguns apontamentos históricos. Tempo, 12(23), 100-122.

Ferreira, R. F. (1999). Uma história de lutas e vitórias: a construção da identidade de um afrodescendente (Tese de Doutorado). Instituto de Psicologia, Universidade de São Paulo, São Paulo.

Guimarães, A. S. A. (1999). Racismo e antirracismo no Brasil. São Paulo, SP: Ed. 34.

Guimarães, A. S. A. (2002). Classes, raças e democracia. São Paulo, SP: Ed. 34.

Guimarães, A. S. A. (2003). Como trabalhar com "raça" em sociologia. Educação e Pesquisa, 29(1), 93-107.

Guimarães, A. S. A. (2005). Racismo e antirracismo no Brasil (2a ed.). São Paulo, SP: Ed. 34.

Hasenbalg, C. (1979). Discriminação e desigualdades raciais no Brasil. Rio de Janeiro, RJ: Graal.

Kaës, R. (2011). Um singular plural: a psicanálise à prova do grupo. São Paulo, SP: Loyola.

Lewis, B. (1982). Race et couleur en pays d'Islam. Paris: Payot.

Martins, H. V. (2009). As ilusões da cor: sobre raça e assujeitamento no Brasil (Tese de doutorado). Instituto de Psicologia, Universidade de São Paulo, São Paulo.

Miranda, M. A. (2004). A beleza negra na subjetividade das meninas "um caminho para as mariazinhas": considerações psicanaliticas (Dissertação de mestrado). Instituto de Psicologia, Universidade de São Paulo, São Paulo.

Munanga, K. (2004). Rediscutindo a mestiçagem no Brasil: identidade nacional versus identidade negra. Belo Horizonte, MG: Autêntica. 
Munanga, K. (Org.). (2005). Superando o racismo na escola. Brasília, DF: Ministério da Educação, Secretaria da Educação Continuada, Alfabetização e Diversidade.

Nascimento, E. L. (2000). O sortilégio da cor: identidade afrodescendente no Brasil (Tese de doutorado). Instituto de Psicologia, Universidade de São Paulo, São Paulo.

Nogueira, I. B. (1998). Significações do corpo negro (Tese de doutorado). Instituto de Psicologia, Universidade de São Paulo, São Paulo.

Nunes, S. S. (2010). Racismo contra negros: um estudo sobre o preconceito sutil (Tese de doutorado). Instituto de Psicologia, Universidade de São Paulo, São Paulo.

Oliveira, I. (1998). As desigualdades raciais vistas pelas crianças e pelos jovens (Tese de doutorado). Instituto de Psicologia, Universidade de São Paulo, São Paulo.

Oliveira, K. R. (2001). Duas histórias de autodeterminação: a construção da identidade de professoras afrodescendentes (Dissertação de mestrado). Instituto de Psicologia, Universidade de São Paulo, São Paulo.

Pena, S. D. J. (2008). Humanidade sem raças? São Paulo, SP: Publifolha.

Pinto, O. P. (2001). Da descoberta de si mesmo à luta contra a exclusão: visões de militantes do movimento negro de São Paulo sobre a questão racial (Dissertação de mestrado). Instituto de Psicologia, Universidade de São Paulo, São Paulo.

Poliakov, L., Delacampagne, C., \& Girard, P. (1977). Le racisme. Paris: Ed. Sehers.

Rosemberg, F. (2000). Educação infantil, gênero e raça. In A. S. A. Guimarães, L. Huntley (Org.), Tirando a máscara: ensaios sobre o racismo no Brasil. São Paulo, SP: Paz e Terra.

Scandiucci, G. (2005). Juventude negro-descendente e a cultura hip hop na periferia de São Paulo: possibilidades de desenvolvimento humano sob a ótica da psicologia analítica (Dissertação de mestrado). Instituto de Psicologia, Universidade de São Paulo, São Paulo.

Schucman, L. V. (2012). Entre o "encardido", o "branco" eo "branquíssimo": raça, hierarquia e poder na construção da branquitude paulistana (Tese de doutorado). Instituto de Psicologia, Universidade de São Paulo, São Paulo.

Schwarcz, L. M. (1996). As teorias raciais, uma construção histórica de finais do século XIX: o contexto brasileiro. In L. M. Schwarcz \& R. S. Queiroz (Org.), Raça e diversidade. São Paulo, SP: Edusp.

Silveira, M. J. (2002). Educação, diferenças e desigualdade: a contribuição da escola neste enfrentamento (Tese de doutorado). Instituto de Psicologia, Universidade de São Paulo, São Paulo.

Souza, I. S. (1991). Resgate da identidade na travessia do movimento negro: arte, cultura e política (Tese de doutorado). Instituto de Psicologia, Universidade de São Paulo, São Paulo.

Wieviorka, M. (1991). L'espace du racisme. Paris: Du Seuil.
Recebido: 22/04/2013

Revisado: $29 / 11 / 2013$

Aceito: $22 / 03 / 2014$ 


\section{ANEXO 1}

Tabela

Informações sobre as teses e dissertações do IPUSP analisadas

\begin{tabular}{|c|c|c|c|c|c|c|}
\hline Ano & Autor & Título & Tipo & Orientador & $\begin{array}{c}\text { Área de } \\
\text { concentração }\end{array}$ & Categoria \\
\hline 2012 & $\begin{array}{l}\text { Eliane Silvia } \\
\text { Costa }\end{array}$ & $\begin{array}{c}\text { Racismo, política } \\
\text { pública e modos de } \\
\text { subjetivação em um } \\
\text { quilombo do Vale do } \\
\text { Ribeira } \\
\end{array}$ & Tese & $\begin{array}{c}\text { Ianni } \\
\text { Scarcelli }\end{array}$ & PST & $\begin{array}{l}\text { Modos de subjetivação do } \\
\text { racismo }\end{array}$ \\
\hline 2012 & $\begin{array}{l}\text { Lia Vainer } \\
\text { Schucman }\end{array}$ & $\begin{array}{c}\text { Entre o "encardido", } \\
\text { o "branco" e o } \\
\text { "branquíssimo": raça, } \\
\text { hierarquia e poder } \\
\text { na construção da } \\
\text { branquitude paulistana }\end{array}$ & Tese & Leny Sato & PST & $\begin{array}{l}\text { Modos de subjetivação do } \\
\text { racismo }\end{array}$ \\
\hline 2010 & $\begin{array}{l}\text { Sylvia da } \\
\text { Silveira } \\
\text { Nunes }\end{array}$ & $\begin{array}{c}\text { Racismo contra negros: } \\
\text { um estudo sobre o } \\
\text { preconceito sutil }\end{array}$ & Tese & $\begin{array}{c}\text { José } \\
\text { Léon Crochík }\end{array}$ & PSA & Denúncia do racismo \\
\hline 2009 & $\begin{array}{l}\text { Hildeberto } \\
\text { Vieira } \\
\text { Martins } \\
\end{array}$ & $\begin{array}{c}\text { As ilusões da cor: sobre } \\
\text { raça e assujeitamento } \\
\text { no Brasil }\end{array}$ & Tese & Eda Tassara & PST & Denúncia do racismo \\
\hline 2005 & $\begin{array}{l}\text { Guilherme } \\
\text { Scandiucci }\end{array}$ & $\begin{array}{l}\text { Juventude negro- } \\
\text { descendente e a } \\
\text { cultura hip hop na } \\
\text { periferia de São } \\
\text { Paulo: possibilidades } \\
\text { de desenvolvimento } \\
\text { humano sob a ótica da } \\
\text { psicologia analítica }\end{array}$ & Dissertação & $\begin{array}{c}\text { Laura } \\
\text { Villares }\end{array}$ & PSA & $\begin{array}{l}\text { Estratégias de superação do } \\
\text { racismo }\end{array}$ \\
\hline 2004 & $\begin{array}{l}\text { Maria } \\
\text { Aparecida } \\
\text { Miranda }\end{array}$ & $\begin{array}{c}\text { A beleza negra na } \\
\text { subjetividade das } \\
\text { meninas "um caminho } \\
\text { para as mariazinhas": } \\
\text { considerações } \\
\text { psicanalíticas }\end{array}$ & Dissertação & $\begin{array}{c}\text { Miriam } \\
\text { Debieux Rosa }\end{array}$ & PSC & $\begin{array}{l}\text { Modos de subjetivação do } \\
\text { racismo }\end{array}$ \\
\hline 2002 & $\begin{array}{c}\text { Maria } \\
\text { Aparecida } \\
\text { Silva Bento }\end{array}$ & $\begin{array}{l}\text { Pactos narcísicos no } \\
\text { racismo: branquitude e } \\
\text { poder nas organizações } \\
\text { empresariais e no poder } \\
\text { público }\end{array}$ & Tese & Iray Carone & PSA & $\begin{array}{c}\text { Modos de subjetivação do } \\
\text { racismo }\end{array}$ \\
\hline 2002 & $\begin{array}{c}\text { Marly de } \\
\text { Jesus Silveira }\end{array}$ & $\begin{array}{l}\text { Educação, diferenças } \\
\text { e desigualdade: a } \\
\text { contribuição da escola } \\
\text { neste enfrentamento }\end{array}$ & Tese & Iray Carone & PSA & Denúncia do racismo \\
\hline 2001 & $\begin{array}{l}\text { Kiusam } \\
\text { Regina } \\
\text { Oliveira }\end{array}$ & $\begin{array}{l}\text { Duas histórias de } \\
\text { autodeterminação: } \\
\text { a construção } \\
\text { da identidade } \\
\text { de professoras } \\
\text { afrodescendentes }\end{array}$ & Dissertação & Eda Custódio & PSA & $\begin{array}{c}\text { Estratégias de superação do } \\
\text { racismo }\end{array}$ \\
\hline
\end{tabular}




\begin{tabular}{|c|c|c|c|c|c|c|}
\hline Ano & Autor & Título & Tipo & Orientador & $\begin{array}{c}\text { Área de } \\
\text { concentração }\end{array}$ & Categoria \\
\hline 2001 & $\begin{array}{c}\text { Osmar de } \\
\text { Paula Pinto }\end{array}$ & $\begin{array}{l}\text { Da descoberta de si } \\
\text { mesmo à luta contra } \\
\text { a exclusão: visões } \\
\text { de militantes do } \\
\text { movimento negro de } \\
\text { São Paulo sobre a } \\
\text { questão racial }\end{array}$ & Dissertação & Iray Carone & PSA & $\begin{array}{c}\text { Estratégias de superação do } \\
\text { racismo }\end{array}$ \\
\hline 2000 & $\begin{array}{l}\text { Elizabeth } \\
\text { Larkin } \\
\text { Nascimento }\end{array}$ & $\begin{array}{c}\text { O sortilégio da } \\
\text { cor: identidade } \\
\text { afrodescendente no } \\
\text { Brasil } \\
\end{array}$ & Tese & $\begin{array}{l}\text { Ronilda } \\
\text { Ribeiro }\end{array}$ & PSA & $\begin{array}{l}\text { Modos de subjetivação do } \\
\text { racismo }\end{array}$ \\
\hline 1999 & $\begin{array}{l}\text { Ricardo } \\
\text { Franklin } \\
\text { Ferreira }\end{array}$ & $\begin{array}{l}\text { Uma história de lutas e } \\
\text { vitórias: a construção } \\
\text { da identidade de um } \\
\text { afrodescendente }\end{array}$ & Tese & $\begin{array}{l}\text { Ronilda } \\
\text { Ribeiro }\end{array}$ & PSA & $\begin{array}{c}\text { Estratégias de superação do } \\
\text { racismo }\end{array}$ \\
\hline 1998 & $\begin{array}{l}\text { Iolanda } \\
\text { Oliveira }\end{array}$ & $\begin{array}{c}\text { As desigualdades } \\
\text { raciais vistas pelas } \\
\text { crianças e pelos jovens }\end{array}$ & Tese & $\begin{array}{l}\text { Kabengele } \\
\text { Munanga }\end{array}$ & PSA & Denúncia do racismo \\
\hline 1998 & $\begin{array}{l}\text { Isildinha } \\
\text { Batista } \\
\text { Nogueira } \\
\end{array}$ & $\begin{array}{l}\text { Significações do corpo } \\
\text { negro }\end{array}$ & Tese & Iray Carone & PSA & $\begin{array}{l}\text { Modos de subjetivação do } \\
\text { racismo }\end{array}$ \\
\hline 1991 & $\begin{array}{l}\text { Irene Sales } \\
\text { Souza }\end{array}$ & $\begin{array}{l}\text { Resgate da identidade } \\
\text { na travessia do } \\
\text { movimento negro: arte, } \\
\text { cultura e política }\end{array}$ & Tese & $\begin{array}{l}\text { Sylvia Leser } \\
\text { de Mello }\end{array}$ & PST & $\begin{array}{c}\text { Estratégias de superação do } \\
\text { racismo }\end{array}$ \\
\hline
\end{tabular}

